\title{
Childhood obesity in Italian primary schools: eating habits, physical activity and perception of weight by parents
}

\author{
Giancarlo Scarafile ${ }^{1}$ \\ 1 PhD Hygiene, Health Public and Food Safety
}

\section{Abstract}

Childhood obesity is the worst not infectious disease in the world with few clinical treatment options. The purpose of this review is to analyze the epidemiological differences related to childhood obesity in the age group of 6-11 years, both in the United States and Italy which are the most affected by this disease. Among the main causes, three were analyzed: eating habits, physical activity and the perception of the body weight of children by their parents. The review also reports a series of targeted measures adopted by specialized physicians whose main aim is to fight and reduce, in the shortest period possible, the prevalence of childhood obesity. Overeating, often unaware of energy dense foods and beverages, and a sedentary lifestyle habits as well the increase of body weight. The wrong timing of meals, jumping breakfast, eating few fruit and vegetables all day long and drinking sugary and/or carbonated drinks are more frequent and deep-rooted habits among children. To correct these habits and promote a healthy eating it is necessary to plan targeted interventions.

\section{Keywords}

Childhood obesity; Eating habits; Phisycal activity 


\section{Introduction}

Childhood obesity is the worst not infectious disease in the world with few clinical treatment options [1]. It has rapidly increased worldwide and in particular way in economically developed countries; in addition most obese children become obese adults and more than half of the obese 6-year-old children remain obese in adulthood, whereas only $10 \%$ of children of the same age and normal weight become obese in adulthood [2,3]. Childhood obesity is caused by the action of multiple modifiable and non-modifiable risk factors. The most common of the first class are: low level physical activity, high frequency of TV watching, computer or other screen media usage, poor dietary quality, snacking while watching TV or doing homework, and over-exposure to advertisements of high-calorie foods [2,4]. The second class ones: genetic and environmental factors, occurred in the pre-natal and postnatal periods, implying an alteration between energy intake and consumption, might play an important role in each subject tendency $[2,3]$. Childhood obesity can also cause several complications at the cardiovascular, endocrine, pulmonary, musculoskeletal and gastrointestinal levels, as well as possible psycho-social consequences [5]. In 2007 the Italian Ministry of Health promoted "OKkio alla SALUTE", national nutritional surveillance system based on biannual cross-sectional surveys and coordinated by the National Institute of Health. It aims to estimate the prevalence of overweight and obesity among primary schoolchildren and to examine the behavioural factors associated [3]. Major findings in terms of determinants of childhood obesity and perception of the weight status by parents are summarize in this paper.

\section{Determinants of childhood obesity}

\section{Eating habits}

The diet is definitely the main factor affecting the rising of obesity; in fact, a diet with a high intake of calories is the cause of the body weight increase which tends to be preserved until adulthood. A healthy and balanced diet with an optimal ratio of fats, proteins and carbohydrates as well as a right distribution of meals during the day contribute to determine and keep a correct nutritional status. Several researches pointed out that one of the risk factors for the onset of overweight in children is not having breakfast, often associated with the trend to taking food out of order during the morning with a greater total intake of calories [3].

In Italy, $9 \%$ of children does not have breakfast, whereas $30.2 \%$ has not balanced breakfast from the quality point of view, that is taking proteins or carbohydrates only. A piece of information to be emphasized is the risk for the children who do not have breakfast (48.5\%) compared to those who have an unbalanced breakfast (36.1\%) or those who have a balanced one (33.5\%) [3]. For the purpose of a correct interpretation of the data, a breakfast is balanced if it includes two classes of foods, the first with protein contents like milk, eggs, yogurt and cheese, and the second with carbohydrates like bread, baked foods and fruit. National data point out that only a minority of $27.5 \%$ of children has an adequate mid-morning snack, whereas $68.2 \%$ of children takes energy-dense foods and mostly those children who do not have breakfast (74.3\%) [3]. A healthy nutrition in childhood reckons on the daily intake of fruit and vegetables, the consumption of which provides a significant amount of vitamins, fibers and minerals and permits the reduction of the energy density of a diet. In this regard, the guidelines of a healthy nutrition suggest to consume at least five daily servings of fruit and/or vegetables. Most foods and beverages widely consumed in children's snacks are: sandwiches (22.6\%), fruit juices (20.9\%), crackers (12.8\%), snacks (12.6\%) and fruit (11.3\%) [3]. As reported in Figure 1, in Italy, 23.2\% of parents affirms that their children do not consume fruit and vegetables every day, while $6.5 \%$ of children only consumes more than 4 servings [3].

Another aspect, to be considered in the context of a healthy nutrition, concerns the consumption of sugary, soft and/or carbonated drinks, assumed as an important cause for the increase of childhood 


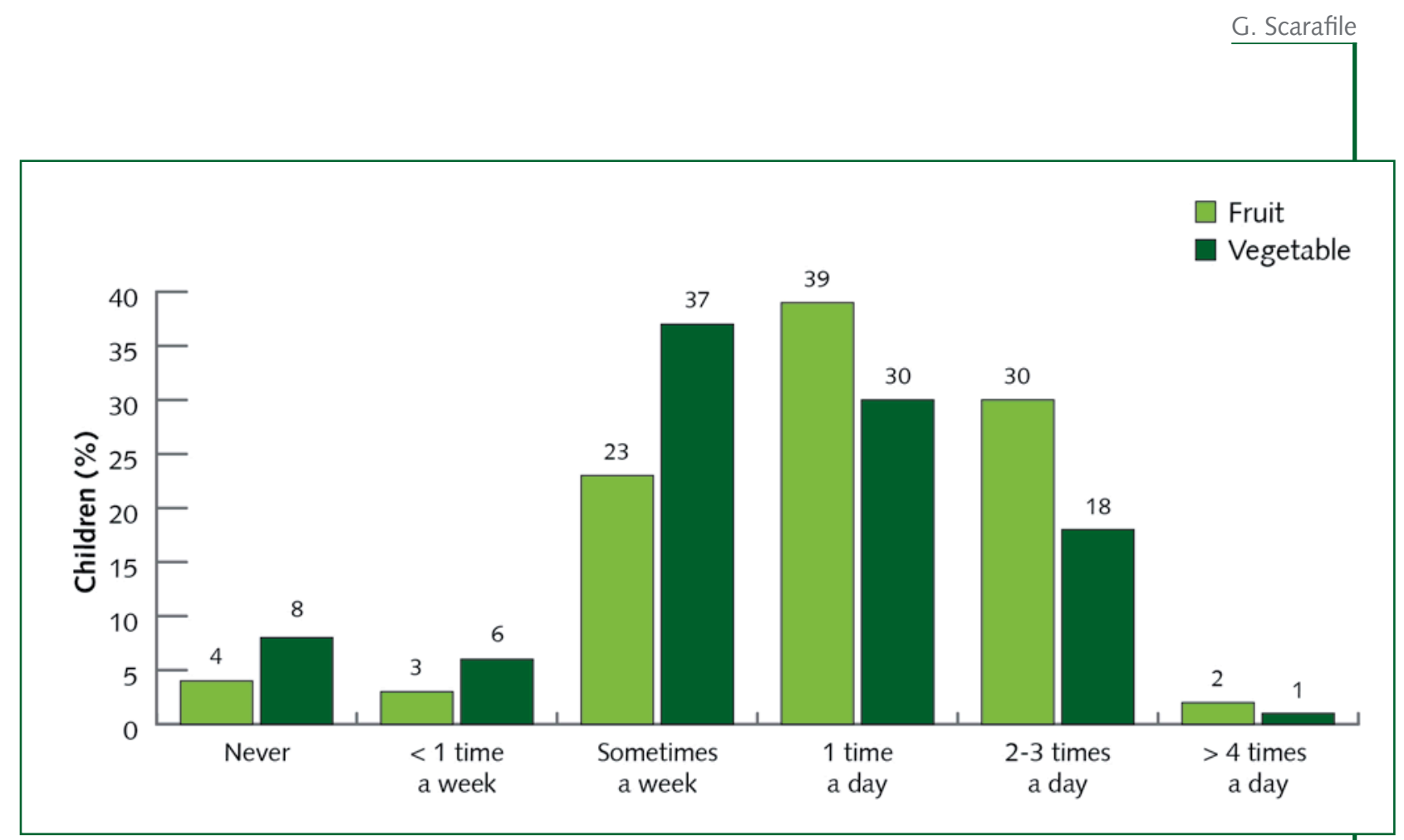

Figure 1. Percentage of distribution of children by eating fruit and vegetables in Italy, 2010. Modified from [3]

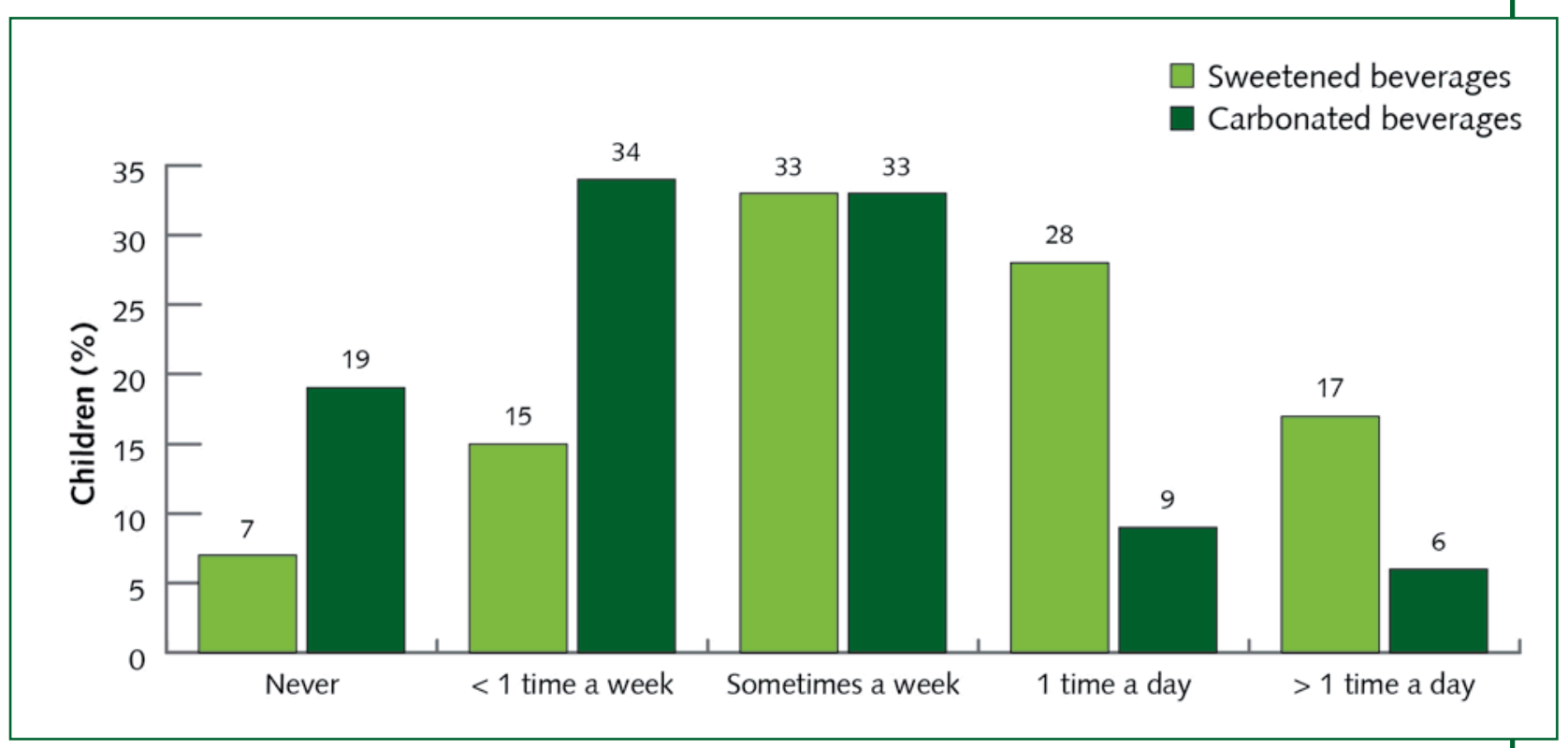

Figure 2. Percentage of distribution of children for consumption of sweetened and carbonated beverages in Italy, 2010. Modified from [3]

obesity. National data assess that $43,8 \%$ of children makes it a daily use, $23.2 \%$ more than once per day (Figure 2) [3].

\section{Physical activity}

The World Health Organization has indicated physical activity as an essential element to control body weight with a positive influence on the health status. Children currently lead a much more sedentary 


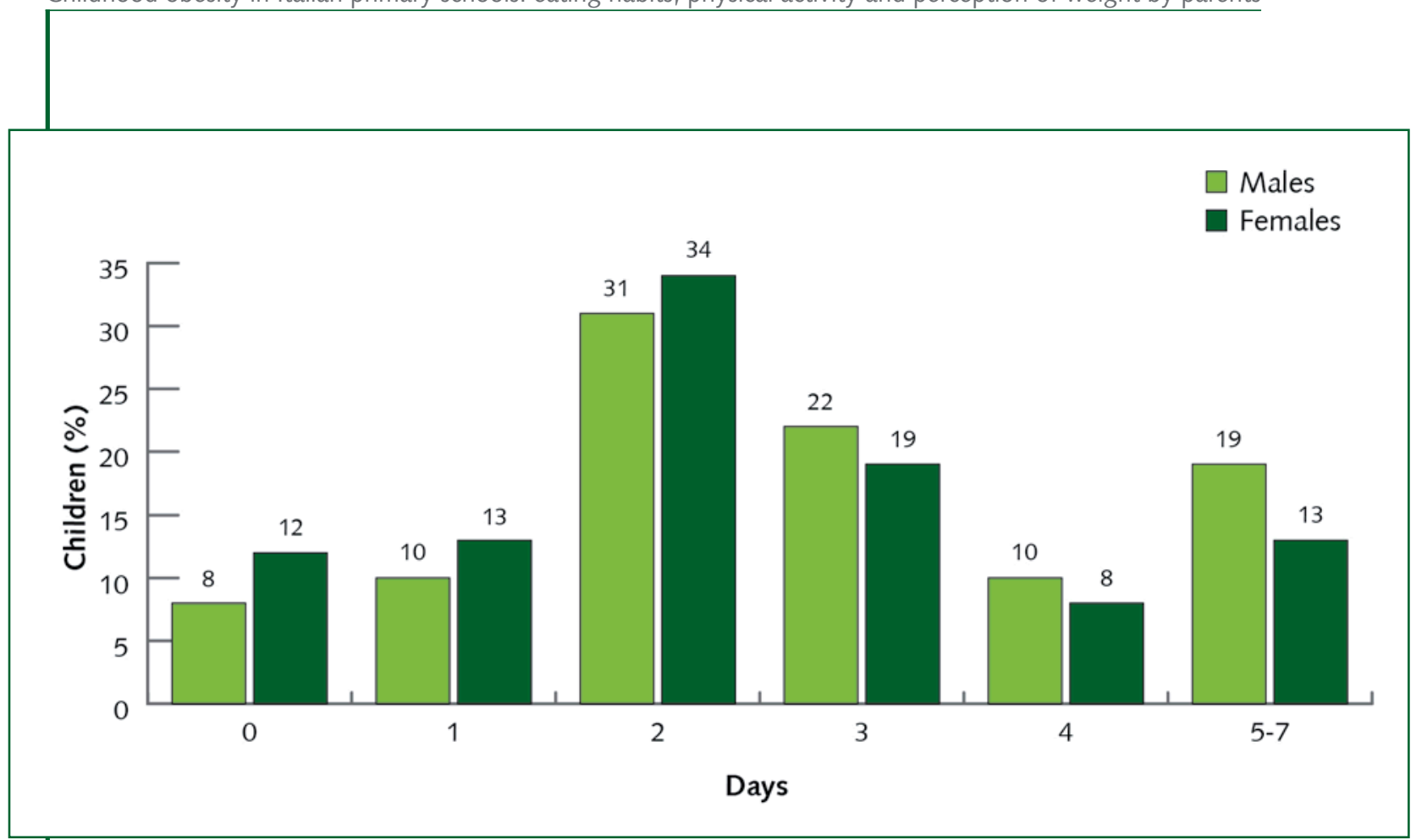

Figure 3. Number of days per week with at least one hour of physical activity, by gender, in Italy 2010. Modified from [3]

lifestyle than their peers of the past times, preferring to spend hours watching television and using computers, activities that facilitate the consumption of high calories foods and lead to weight gain and to obesity [3]. National data show that $83 \%$ of children defined "active", that is engaged in physical outdoor activity in a structured way, attends schools where there are initiatives promoting physical activity [3]. Furthermore, the analysis on the prevalence of children defined "non-active", in relation to some characteristics of the school environment, allowed the identification of additional and important differences; in fact, in schools where at least 2

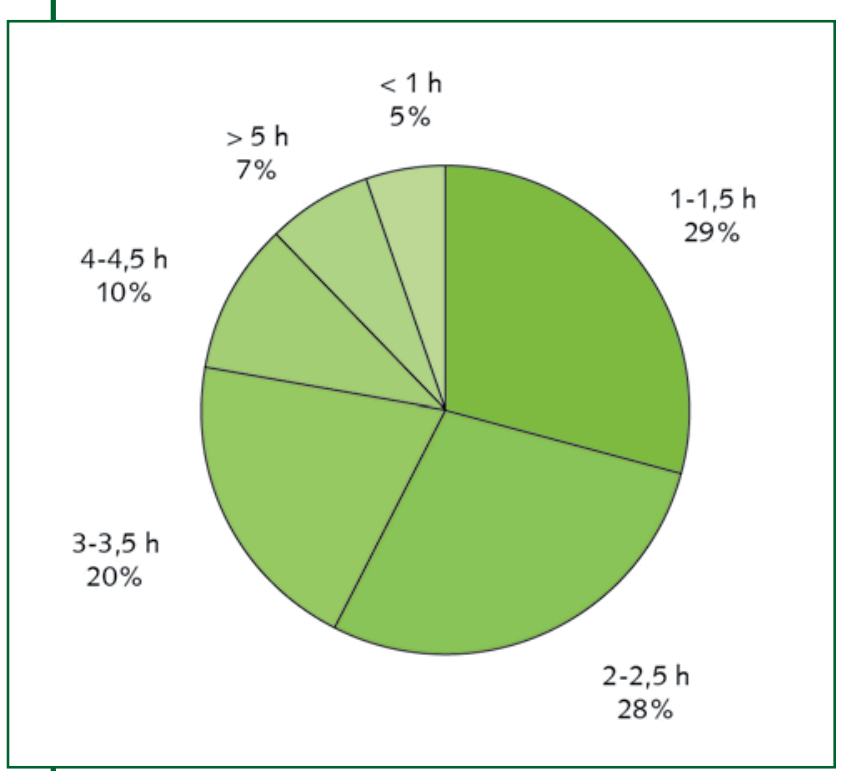

Figure 4. Percentage distribution of time devoted to television or video games in Italy, 2010. Modified from [3] hours of weekly physical activity are performed, the "non-active" children are to a lesser extent (17\%) than those who attend schools that do not offer such an opportunity (20\%) [3].

Similarly, in schools where initiatives are undertaken to promote physical activity, the percentage of "non-active" children is significantly lower (17\%) than those who attend schools that do not offer these possibilities (25\%) [3]. Analyzing the data in a more specific way, it can be said that the percentage of children who normally carries out physical activity has decreased to no more than 1 hour per week $(22 \%)$ and the percentage of children who practices it with continuity (from 4 to 7 days) has increased (25\%) [3].

A parameter to be considered, which is in contrast to physical activity, is definitely the time spent by children in sedentary activities such as watching TV and playing videogames. 
As to Italy, the data point out that $62 \%$ of children dedicates up to 2 hours and 30 minutes per day, $30 \%$ from 3 to 4 hours and 30 minutes, and 7\% over 5 hours per day to these activities [3]. Another aspect to consider in data processing involved the presence of the TV set in the children's room; nationwide, $46 \%$ has a TV in its room [3] (Figure 4).

Finally, information were collected on the way home/school and any means of transport used. It came out that $26 \%$ only reaches school on foot, $60 \%$ by car, $12 \%$ by bus, $2 \%$ by bicycle and $2 \%$ in any other way [3].

\section{Perception of the weight status by parents}

National nutritional surveillance system data (Figure 5) point out that $47 \%$ of mothers of overweight children and $11 \%$ of obese ones consider their children normal or underweight and $12 \%$ only of mothers of obese children perceive the real status of obesity [3]. Another factor which may affect the maternal perception is the weight status of the mother herself: $42 \%$ of normal/underweight women classify correctly their children, whereas such a percentage drops to $35 \%$ for women who are overweight or obese [3].

When analyzing epidemiological data in a more general way, the presence of an overweight or obese parent is associated with a less accurate perception: the percentage of children perceived in a distorted way by their mothers is equal to $65 \%$ in households where at least one parent is obese, to $61 \%$ in those with at least one overweight parent, and to 55\% in families with two parents of normal and/or underweight [3]. With regard to nutrition, the data of 2010 confirm, as in the past, that a condition of excess weight does not often correspond to a perception of excess in food intake. Particularly, women who think that their children are overfed are $11 \%$ of mothers of overweight children and $48 \%$ of obese ones [3].

This figure could partly depend on the modification of the diet of overweight or obese children by decreasing the quantity consequently to their excess weight.

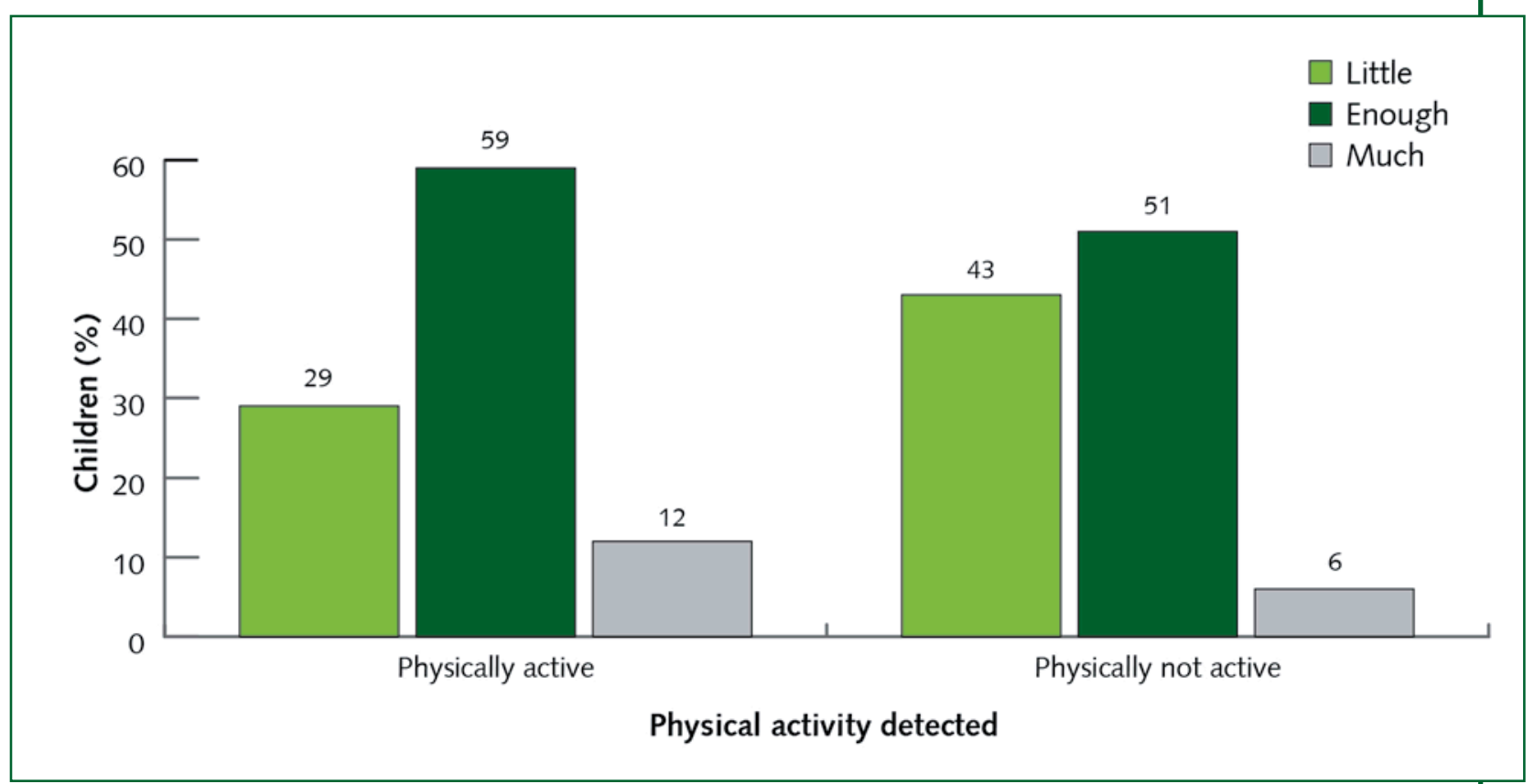

Figure 5. Percentage distribution of the opinion expressed by the mothers as to physical activity of their children, for the actual level of activity in Italy, 2010. Modified from [3] 
As concerns physical activity, it was found that $57 \%$ of mothers of children classified "less active" (that is, not engaged in any sport or game outdoor or in physical activities at school, even the day before investigation) believes that their children carry on a sufficient physical activity [3].

\section{Aim of the review}

The purpose of this study is to analyze the epidemiological differences related to childhood obesity in the age group of 6-11 years, both in the United States and Italy. The review also reports a series of targeted measures adopted by specialized physicians whose main aim is to fight and reduce, in the shortest period possible, the prevalence of childhood obesity

\section{Search of the Literature}

A number of full text articles published in English from 1998 to 2013 have been reviewed. The first search on the site PubMed allowed initially to collect 8.762 articles. The PubMed database has been considered for the bibliographic research and the following key words were applied: "childhood obesity" , "childhood obesity epidemiology", "food and physical activity in primary schools". The exclusion criteria were: comments, letters to publishers, reviews and studies carried out before 1998. From each selected study, the following data were collected: geographic location, year of publication, study period, type of study, the age of sample selected from 6 to 11 years old.

\section{Results and discussion}

The aim of this study is to analyze the epidemiological differences concerning childhood obesity in the age group of 6-11 years, in the U.S.A. and Italy, where the prevalence of the disease is respectively: $19,6 \%[6-11]$ and $12 \%[3,5,12,13]$. Among the main causes, three were analyzed: eating habits, physical activity and perception of children weight status by parents. The motivation leading to this decision is linked to the publication of several studies which have highlighted the great influence of these three causes more than others as economical, social, familial and hereditary ones. Taking into consideration the reviews through the years 1998-2013, we could study and compare two realities different from each other in some respects, but at the same time this comparison was helpful to understand not only the motivations and the causes that have enabled childhood obesity to spread so rapidly over the time, but also the measures taken by countries to effectively contrast it. A careful study of data shows how the diet of the children in both countries is the most direct cause of obesity, and this for several reasons; firstly, breakfast, the main meal of the day, is not taken by all the children and is often not balanced under the qualitative aspect as well, that is assuming glucides or carbohydrates $[3,4,9,14]$. Several studies have shown how not having breakfast expose children to a higher risk of obesity than those who do not jump the meal, as it forces them to take food very rich in proteins in the hours of morning, particularly during school time. The consequence of this is a strong caloric imbalance that increases over time and becomes hardly curable as they get older $[3,5,13,15]$. The consumption of fruit and vegetables, rich in fibers, is very low; only a small percentage of children consumes 5 servings per day as recommended by the guidelines on a healthy eating, unfortunately, they have been replaced by carbonated and sugary drinks, more palatable but with a lower intake of vitamins [6,16-18]. A recent study carried out in Italy demonstrates the evidence of a statistically significant inverse association between frequency of milk consumption and body mass in a large sample of children. This association is independent of 
other possible determinants of body mass, such as age, birth weight, parental overweight, education of parents, physical activity and reported dietary habits. Finally the prevalence of overweight is lower in children consuming whole milk daily than in those who consume milk less frequently [19].

A factor common to the two countries concerns the increasingly widespread presence of vending machines in schools, wherefrom it is possible to buy junk food, that is food rich in calories but poor in nutritional supply, as snacks, filled snacks and sweets $[9,13,15,20]$. An important factor to be considered in the USA is that a lot of children buy their food in corner store environments close to schools, fast foods which are mainly sold packaged such as: beverage, candies, gums, chips, frozen treats, pastries, egg rolls, all of them with a high level of proteins and calories. The only fresh food sold are prepared sandwiches [14,21].

According to the OMS, physical activity is the only factor able to control body weight and, associated with a healthy and balanced diet, it becomes a valuable factor against childhood obesity [22]. The US Dietary Guidelines for Americans recommend that young people (ages 6-19) should participate in at least 60 minutes of moderate-to-vigorous physical activity, even if not all days of the week, and the Health in the Balance report Institute of Medicine's Preventing Childhood Obesity recommends that all students have to be given the opportunity to participate in at least 30 minutes of physical activity during the school day [23]. Unfortunately, children participating in after-school programs are engaged in 20 minutes only of moderate to vigorous physical activity with most of their time spent in light or sedentary activities $[11,18]$.

The comparison of data between the two countries gives a picture of an unpredictable situation; in fact, while in Italy the percentage of children engaged in physical activity out of the school time and mainly in a continuous way, that is from 4 to 6 sessions per week is increased, in the U.S.A., where schools have represented an ideal environment to start physical activity, we are now witnessing a decrease of schools that require its carrying out, as one out of five does not any more consider physical education a curricular subject, not allowing its students to practice it every day [24]. Different studies have shown important results in obese children who agreed to participate in after school activities such as: schoolcamping, where children with obesity reduced fat mass and redistribution of adipose tissue, increased lean mass and reduced insulin and glycemic levels. Another aspect to consider is participating in physical activity for at least three hours a day [22].

The turnaround is also evident at political-institutional level; data show that only 7 out of 10 states encourage schools to introduce targeted programs. The reason of this radical change is due to a different school policy which prefers to give priority to the evaluation of students in traditional subjects and penalize those who try to make up for the gaps with the practice of physical activity. In short, sport is no longer considered a lever to be used to disrupt educational meritocracy, the agonistic results each school aimed at are now in the background. This factor pushes schools to adopt a different approach in the practice of physical education, relying on a team of qualified people who, using technological devices, are able to draw up individual programs for students not only of healthy weight but even for the obese ones, looking for the families' involvement, too [25].

The third aspect concerns the perception of children's body weight by parents and, with regard to this, the compared data of the two countries are similar. The health conditions of the children is almost always monitored by their mothers who reveal a widespread inability to recognize the actual weight of the children for several reasons: the presence in the family of an obese parent, or both, very rarely leads a mother to consider obese a child with excessive weight; the socio-economical condition of the family has a negative impact on the actual awareness of the disease with a lacking acknowledgement of the relationship between overweight and high-calorie diet [26]. It should also be noted that underestimation of obesity stems from the fact that most families do not know the parameters and the measurement methods to be applied for the recognition of the disease and, consequently, to consider childhood obesity a public health problem which cannot be individually faced $[21,26]$. 


\section{Conclusions}

This review has highlighted the most common causes of childhood obesity in the two countries, which are in the world, the most affected by this disease. Overeating, often unaware of energy dense foods and beverages, and a sedentary lifestyle favour as well the increase of body weight [27]. As above mentioned, the wrong timing of meals, jumping breakfast, eating few fruit and vegetables all day long and drinking sugary and/or carbonated drinks are, in fact, more frequent and deep-rooted habits among children. To correct these habits and promote a healthy eating it is necessary to plan targeted interventions $[7,8]$.

The first step may be informing the children's families about the usefulness and importance of a healthy and balanced diet that includes breakfast, daily consumption of fruit and vegetables, use of water as the main and sufficient source of liquids, and provide children with adequate portions for their age, as to quantity and nutritional supply [28]. It would be useful to continue with the approach recently adopted by the two countries, stimulating the production of foods having low contents of fat and sugar, regulating the sales promotions aimed at children, ensuring healthy school meals including the removal of vending machines.

The data related to physical activity confirm a situation that in recent years has been getting worse and worse and, therefore, far from national and international recommendations. In fact, the daily practice of physical activity, considered as a game of movement and/or structured sports activities, is not very common, whereas sedentary behaviours, such as watching TV or playing videogames for several hours a day, are widespread [10,29-31]. Lack of physical activity and increased sedentary lifestyle can be contrasted by adopting several strategies of intervention not exclusively aimed at the individual. An important place for the promotion of policies of intervention is definitely school, where children spend $40 \%$ of their time; improving the way from home to school, creating cycle tracks, increasing the sessions of physical education in the school curriculum may prove to be winning strategies [4,12,32-34]. The first step to reduce childhood obesity is the collective awareness that the problem of overweight exists, involves all the family and is deeply rooted. In modern society there is still no understanding of why and how unsuited eating habits and lifestyles are the causes of excess weight and how these may

Questions for further research

- Inform and mobilize public opinion, make more informed and responsive opinion on the consequences for public health, on the social and economic costs and environmental obesity.

- Set a joint commitment of governments and the private sector, enable integrated plans and coordinated medium and long term for the fight against obesity, involving all major stakeholders.

- Spread the culture of prevention, educate people to the concept of limit and transmit the culture of prevention so that healthy behaviors become increasingly a conscious choice.

- Teach healthy habits from childhood. Strengthen the principals of education and information youth.

- Use a balanced price lever. Carefully evaluate the pros and cons introducing tax disincentives such as taxes on junk food.

- To encourage the efforts of industry and distribution, involve the food industry and distribution in public health initiatives promoted and led by governments.

- Tackling the obesogenic environment. The factors that lead to assume styles life and incorrect food choices and make it difficult to make healthy choices.

- Improve scientific knowledge available, through investments in applied research and creation of joint university-industry groups, which can lead to improve the understanding of the links between obesity and a number of external variables (environment, school, communication campaigns). 
consequently have a negative impact on the health of population. The overweight of their children is a very difficult condition to be recognized by parents, as well food intake and lack of physical activity. To achieve positive results in the fight against childhood obesity, we need to create an information network involving in a decisive manner families and pediatricians, whose task shall be twofold: periodical checkup of the child's weight and, in case of detection of the disease, start the appropriate treatment. The contribution of the pediatricians has so far been neglected. Intervention to promote health and fight childhood obesity, therefore, should not be targeted exclusively to children but should also directly engage families.

The review in brief

Clinical Childhood obesity is the worst not infectious disease in the world with few clinical treatment options. question The purpose of this study is to analyze the epidemiological differences related to childhood obesity in the age group of 6-11 years, both in the United States and Italy. The review also reports a series of targeted measures adopted by specialized physicians whose main aim is to fight and reduce, in the shortest period possible, the prevalence of childhood obesity.

Type of the Narrative

review

Search of the PubMed (keywords: "childhood obesity", "childhood obesity epidemiology", "food and physical activity in literature primary schools")

Conclusion This review has highlighted the most common causes of childhood obesity in the two countries, which are in the world, the most affected by this disease. Overeating, often unaware of energy dense foods and beverages, and a sedentary lifestyle habits as well the increase of body weight. The wrong timing of meals, jumping breakfast, eating few fruit and vegetables all day long and drinking sugary and/or carbonated drinks are more frequent and deep-rooted habits among children. To correct these habits and promote a healthy eating it is necessary to plan targeted interventions.

Limitations Studies of children with feeding problems, eating disorders or medical diagnoses have been excluded.

\section{References}

1. Siwik V, Kutob R, Ritenbaugh $\mathrm{C}$, et al. Intervention in overweight children improves body mass index (BMI) and physical activity. JABFM 2013; 26: 126-37; http://dx.doi.org/10.3122/ jabfm.2013.02.120118

2. Bracale R, Milani L, Ferrara E, et al. Childhood obesity, overweight and underweight: a study in primary schools in Milan. Eat Weight Disord 2013; 18: 183-91; http://dx.doi.org/10.1007/s40519013-0036-9

3. Spinelli A, Lamberti A, Nardone P, et al. Sistema di sorveglianza OKkio alla SALUTE: risultati 2010. Roma: Istituto Superiore di Sanità, 2012 (Rapporti ISTISAN 12/14)

4. Gonzalez W, Jones S, Frongillo E. Restricting snacks in U.S. elementary schools is associated with higher frequency of fruit and vegetable consumption. The Journal of Nutrition 2009; 139: 142-4; http://dx.doi.org/10.3945/jn.108.099531

5. Lazzeri G, Pammolli A, Pilato V, et al. Relationship between 8/9-yr-old school children BMI, parents' BMI and educational level: a cross sectional survey. Nutrition Journal 2011; 10: 76; http:// dx.doi.org/10.1186/1475-2891-10-76 
6. Cunningham S, Zavodny M. Does the sale of sweetened beverages at school affect children's weight? Social Science \& Medicine 2011; 73: 1332-9; http://dx.doi.org/10.1016/j.socscimed.2011.08.003

7. Fernandes M, Sturm R. The role of school physical activity programs in child body mass trajectory. J Phys Act Health 2011; 8: 174-81

8. Fernandes M, Sturm R. Facility provision in elementary schools: correlates with physical education, recess, and obesity. Prev Med 2010; 50(Suppl 1): 30-5; http://dx.doi.org/10.1016/j. ypmed.2009.09.022

9. Finkelstein D, Hill E, Whitaker R. School Food Environments and Policies in US Public Schools. Pediatrics 2008; 122: e251-9; http://dx.doi.org/10.1542/peds.2007-2814

10. Huberty J, Balluff M, O'Dell M, et al. From good ideas to actions: A model-driven community collaborative to prevent childhood obesity. Prev Med 2010; 50(Suppl 1): S36-43; http://dx.doi. org/10.1016/j.ypmed.2009.08.013

11. Ogden C, Carroll M, Curtin L, et al. Prevalence of high body mass index in US children and adolescents, 2007-2008. JAMA 2010; 303: 242-9; http://dx.doi.org/10.1001/jama.2009.2012

12. Battista J, Nigg C, Chang J, et al. Elementary After School Program: An Opportunity to Promote Physical Activity for Children. Californian J Health Promot 2005; 3: 108-18

13. Lazzeri G, Rossi S, Pammolli A, et al. Underweight and overweight among children and adolescents in Tuscany (Italy).Prevalence and short-term trends. J Prev Med Hyg 2008; 49: 13-21

14. Borradaile K, Sherman S, Vander Veur S, et al. Snacking in Children: The Role of Urban Corner Stores. Pediatrics 2009; 124: 1293-8; http://dx.doi.org/10.1542/peds.2009-0964

15. Kubik M, Wall M, Shen L, et al. State but not District Nutrition Policies are associated with less junk food in vending machines and school stores in US public schools. J Am Diet Assoc 2010; 110: 1043-8; http://dx.doi.org/10.1016/j.jada.2010.04.008

16. Cullen K, Zakeri I. Fruits, vegetables, milk, and sweetened beverages consumption and access to a la carte/snack bar meals at school. Am J Public Health 2004; 94: 463-7; http://dx.doi.org/10.2105/ AJPH.94.3.463

17. Fernandes M. The Effect of Soft Drink Availability in Elementary Schools on Consumption. J Am Diet Assoc 2008; 108: 1445-52; http://dx.doi.org/10.1016/j.jada.2008.06.436

18. O'Toole T, Anderson S, Miller C, et al. Nutrition Services and Foods and Beverages Available at School: Results From the School Health Policies and Programs Study 2006.

19. J Sch Health 2007; 77: 500-21; http://dx.doi.org/10.1111/j.1746-1561.2007.00232.x

20. Barba G, Toiano E, Russo $P$, et al. Inverse association between body mass and frequency of milk consumption in children. Br J Nutr 2005; 93: 15-9; http://dx.doi.org/10.1079/BJN20041300

21. Datar A, Nicosia N. Junk Food in Schools and Childhood Obesity. J Policy Anal Manage 2012; 31: 312-37; http://dx.doi.org/10.1002/pam.21602

22. Shier V, An R, Sturm R. Is there a robust relationship between neighbourhood food environment and childhood obesity in the USA? Public Health 2012; 126: 723-30; http://dx.doi.org/10.1016/j. puhe.2012.06.009

23. Di Pietro M, Campanaro P, D’Angelo G, et al. Role of camping in the treatment of childhood obesity. Acta Bio Medica Ateneo Parmense 2004; 75: 118-21

24. Lee S, Burgeson C, Fulton J, et al. Physical Education and Physical Activity: Results from the School Health Policies and Programs Study 2006. J Sch Health 2007; 77: 435-63; http://dx.doi. org/10.1111/j.1746-1561.2007.00229.x

25. Perez A, Hoelscher D, Springer A, et al. Physical activity, watching television, and the risk of Obesity in students, Texas, 2004-2005. Prev Chronic Dis 2011; 8: 1-11

26. Lanier W, Wagstaff R, DeMill J, et al. Teacher awareness and implementation of food and physical activity policies in Utah elementary schools,2010. Prev Chronic Dis 2012; 9: E18

27. Perrin E, Jacobson Vann J, Benjamin J, et al. Use of pediatrician toolkit to address parental perception of children's weight status, nutrition, and activity behaviors. Acad Pediatr 2010; 10: 274-81; http://dx.doi.org/10.1016/j.acap.2010.03.006 
28. Yin Z, Moore J, Johnson M, et al. The Impact of a 3-year after-school obesity prevention program in elementary school children. Chilhood obesity 2012; 8: 60-70

29. Wang Y, Ludwig D, Sonneville K, et al. Impact of change in sweetened caloric beverage consumption on energy intake among children and adolescents. Arch Pediatr Adolesc Med 2009; 163: 336-43; http://dx.doi.org/10.1001/archpediatrics.2009.23

30. Iversen C, Nigg C, Titchenal A. The Impact of an elementary after-school nutrition and physical activity program on children's fruit and vegetable intake, physical activity, and body mass index: fun 5. Hawaii Med J 2011; 70(7 suppl 1): 37-41;

31. Matheson D, Killen J, Wang Y, et al. Children's food consumption during television viewing. Am J Clin Nutr 2004; 79: 1088-94

32. Veerman J, Van Beeck E, Barendregt J, et al. By how much would limiting TV food advertising reduce childhood obesity? Eur J Public Health 2009; 19: 365-9; http://dx.doi.org/10.1093/eurpub/ ckp039

33. Cawley J, Meyerhoefer C, Newhouse D. The Impact Of State Physical Education Requirements On Youth Physical Activity And Overweight. Health Econ 2007; 16: 1287-1301

34. Datar A, Sturm R. Physical education in elementary school and body mass index: evidence from he early childhood longitudinal study. Am J Public Health ; 2004; 94: 1501-6; http://dx.doi. org/10.1002/hec.1218

35. Jordan A, Hersey J, McDivitt J, et al. Reducing children's television-viewing time: a qualitative study of parents and their children. Pediatrics 2006; 118: e1303-10; http://dx.doi.org/10.1542/ peds.2006-0732

\section{Acknowledgements}

Special thanks to the Institute of Health (ISS, Rome,Italy) for their willingness to grant copyright for graphics inserted in the article, without which it would be impossible to write this review. 